\title{
MIGRATORY STATE: BODY MASS AND FAT LEVEL OF SOME PASSERINE LONG-DISTANCE MIGRANTS DURING AUTUMN MIGRATION IN NORTH-EASTERN BULGARIA
}

\author{
Mihaela Ilieva and Pavel Zehtindjiev
}

\begin{abstract}
Ilieva M., Zehtindjiev P. 2005. Migratory state: body mass and fat level of some passerine longdistance migrants during autumn migration in north-eastern Bulgaria. Ring 27, 1: 61-67.

Body condition of 3224 migrating birds of Great Reed Warbler (Acrocephalus arundinaceus), Sedge Warbler (A. schoenobaenus), Willow Warbler (Phylloscopus trochilus), Red-backed Shrike (Lanius collurio) and Whitethroat (Sylvia communis) was studied at Kalimok Station, NE Bulgaria ( $\left.41^{\circ} 00^{\prime} \mathrm{N} 26^{\circ} 26^{\prime} \mathrm{E}\right)$ in the autumns of $1997-2003$. The mean values of the fat level and the body mass were calculated for each species and year and were compared with similar data of various parts of the Palaearctic-African Migration System. Distinct variations in the mean values of studied parameters in different years were recorded. The dynamics of the accumulated subcutaneous fat and the body mass during the autumn varied in different species and either increase or decrease of the values during a certain season were registered. Agedetermined differences in the studied characteristics were found. The timing of the passage of the first-year and adult birds can influence the dynamics of the mean fat level and the mean body mass. The lack of selective environment in NE Balkan Peninsula allows the passage of conspecific birds in various migratory states. The realisation of their migration adaptations highly depends on environmental conditions during the period of passage.
\end{abstract}

M. Ilieva and P. Zehtindjiev, Insitute of Zoology, Bulgarian Academy of Sciences, Blvd. Tzar Osvoboditel 1, 1000 Sofia, Bulgaria, Tel. (+3592) 988-51-15, Fax (+3592) 973-38-37, E-mail: michaela_ilieva@yahoo.com

Publication appointed to the SE European Bird Migration Network papers

Key words: bird migration, Balkan Region, body mass, fat level, long-distance migrants

\section{INTRODUCTION}

The accumulation of considerable amount of energy reserves is a typical feature of the long-distance migrants, which have to cross large ecological barriers like the Mediterranean Sea and Sahara in their way to wintering grounds (Dolnik 1975, Berthold 2001). Therefore, the physiological parameters such as the body mass and 
the fat level are frequently used indicators of energetic reserves of birds during migrations. In western and northern Europe as well as in Sahara, a significant number of studies concerning fat accumulation of trans-Saharan migrants have been carried out (Biebach 1990, Bairlein 1992, Akesson et al. 1995, Schaub and Jenni 2000). In contrast, the Balkan Peninsula is still a white spot and only data on some local populations are available (Akriotis 1998).

The aim of the present study is to characterise the physiological condition of the species studied at a point along the East-European migratory flow during the autumn migration. On the basis of these data, we also attempt to answer the question: Do mean values of the fat level and the body mass indicate particular migration strategies of the species or are they simple responses to the ecological conditions during the current season?

\section{MATERIAL AND METHODS}

The present study is a part of a complex research program on the passerine migration started in 1995 in the Balkan Region. The data was collected during the periods from the beginning of August to the middle of October in 1997-2003 at Kalimok Field Station situated near Danube riverbank in NE Bulgaria $\left(41^{\circ} 00^{\prime} \mathrm{N}\right.$ $26^{\circ} 26^{\prime} \mathrm{E}$ ). Birds were mist-netted in two main habitats, the area of former fishponds overgrown by reeds (Phragmites communis) and the deciduous mixed forest (Robinia pseudoacacia and Fraxinus oxycarpa). For 7 autumn seasons, 3224 birds of the Great Reed Warbler (Acrocephalus arundinaceus), Sedge Warbler (Acrocephalus schoenobaenus), Willow Warbler (Phylloscopus trochilus), Red-backed Shrike (Lanius collurio) and Whitethroat (Sylvia communis) were ringed and measured according to ESF (European Science Foundation) project (Bairlein 1995) and SEEN (South East European Bird Migration Network) standards (Busse 2000) - see Table 1 . For the purposes of the present study, the body mass (to the nearest $0.5 \mathrm{~g}$ ), the visible fat reserves estimated on a nine-class scale (Kaiser 1993) and the body feathers moult intensity in a three-score scale $(0$ - no feathers growing, 1 - between 1 to 20 feathers growing, 2 - more than 20 feathers growing) were used. Moulting birds scored with 2 were not included into the analysis.

Table 1

Numbers of individuals studied

\begin{tabular}{|l|c|c|c|c|c|c|c|r|}
\hline & 1997 & 1998 & 1999 & 2000 & 2001 & 2002 & 2003 & Total \\
\hline Acrocephalus arundinaceus & 40 & 16 & 141 & 35 & 244 & 88 & 118 & $\mathbf{8 6 8}$ \\
\hline Acrocephalus schoenobaenus & 69 & 10 & 249 & 188 & 267 & 127 & 147 & $\mathbf{1 0 5 7}$ \\
\hline Phylloscopus trochilus & 16 & 48 & 109 & 197 & 193 & 111 & 98 & $\mathbf{7 7 2}$ \\
\hline Lanius collurio & 19 & 74 & 51 & 83 & 78 & 37 & 69 & $\mathbf{4 1 1}$ \\
\hline Sylvia communis & 6 & 8 & 30 & 79 & 98 & 31 & 50 & $\mathbf{3 0 2}$ \\
\hline Total & $\mathbf{1 5 0}$ & $\mathbf{1 5 6}$ & $\mathbf{5 8 0}$ & $\mathbf{5 8 2}$ & $\mathbf{8 8 0}$ & $\mathbf{3 9 4}$ & $\mathbf{4 8 2}$ & $\mathbf{3 2 2 4}$ \\
\hline
\end{tabular}




\section{RESULTS}

\section{Fat level}

For the five studied species, the means of the fat level for each year were obtained (Table 2). The Great Reed Warbler showed relatively constant and the lowest mean fat levels $(2.5 \pm 1.8$, range $=2.0-2.9)$ while the Whitethroat had the highest mean fat score and great variation in the mean values between the years $(3.9 \pm 1.8$, range $=3.0-4.8)$. We also observed considerable variations in the fat levels between different seasons in all studied species. No general pattern in the dynamics of the fat depositions representative for all the species at the same time was found. Neither years of good conditions nor years with bad ones were identified for the studied species considered together.

Table 2

Fat scores $($ mean $\pm S D)$

\begin{tabular}{|l|c|c|c|c|c|c|c|c|}
\hline & 1997 & 1998 & 1999 & 2000 & 2001 & 2002 & 2003 & Total \\
\hline A. arundinaceus & $2.3 \pm 1.8$ & $2.1 \pm 2.2$ & $2.0 \pm 1.7$ & $2.8 \pm 2.0$ & $2.9 \pm 1.8$ & $2.9 \pm 1.7$ & $2.3 \pm 1.9$ & $\mathbf{2 . 5} \pm \mathbf{1 . 8}$ \\
\hline A. schoenobaenus & $3.5 \pm 2.1$ & $2.8 \pm 1.0$ & $3.1 \pm 1.7$ & $2.5 \pm 1.9$ & $3.7 \pm 1.9$ & $4.0 \pm 2.0$ & $3.2 \pm 2.1$ & $\mathbf{3 . 3} \pm \mathbf{1 . 9}$ \\
\hline Ph. trochilus & $3.2 \pm 1.2$ & $3.9 \pm 1.2$ & $2.7 \pm 1.8$ & $3.5 \pm 2.0$ & $3.5 \pm 1.8$ & $4.3 \pm 1.7$ & $4.0 \pm 1.8$ & $\mathbf{3 . 4} \pm \mathbf{1 . 9}$ \\
\hline L. collurio & $3.0 \pm 2.1$ & $2.9 \pm 1.9$ & $2.6 \pm 1.6$ & $1.9 \pm 1.9$ & $3.6 \pm 2.0$ & $3.8 \pm 2.3$ & $2.2 \pm 2.0$ & $\mathbf{2 . 7} \pm \mathbf{2 . 0}$ \\
\hline S. communis & $4.5 \pm 1.1$ & $4.8 \pm 1.8$ & $3.0 \pm 1.6$ & $4.4 \pm 1.8$ & $3.7 \pm 1.7$ & $4.6 \pm 1.7$ & $3.5 \pm 1.8$ & $\mathbf{3 . 9} \pm \mathbf{1 . 8}$ \\
\hline
\end{tabular}

\section{Body mass}

The body mass mean values of the five studied species for each year (Table 3) showed considerable variations. They corresponded to the variations of the fat levels and did not follow a general pattern for all the species. According to the standard deviation, the body mass values are less variable compared with those of the fat level.

Table 3

Body mass (mean $\pm S D)$

\begin{tabular}{|l|c|c|c|c|c|c|c|c|}
\hline & 1997 & 1998 & 1999 & 2000 & 2001 & 2002 & 2003 & Total \\
\hline A. arundinaceus & $28.5 \pm 4.7$ & $30.8 \pm 5.2$ & $28.5 \pm 3.7$ & $29.0 \pm 3.9$ & $29.4 \pm 4.7$ & $29.3 \pm 4.1$ & $29.0 \pm 4.3$ & $\mathbf{2 9 . 1} \pm \mathbf{4 . 3}$ \\
\hline A. schoenobaenus & $11.9 \pm 2.6$ & $11.0 \pm 0.8$ & $11.8 \pm 1.5$ & $11.5 \pm 1.5$ & $12.0 \pm 1.8$ & $12.7 \pm 2.2$ & $12.1 \pm 1.8$ & $\mathbf{1 1 . 9} \pm \mathbf{1 . 8}$ \\
\hline Ph. trochilus & $8.5 \pm 1.1$ & $9.6 \pm 1.2$ & $9.3 \pm 1.6$ & $9.6 \pm 1.6$ & $9.1 \pm 1.5$ & $10.4 \pm 1.9$ & $9.9 \pm 1.7$ & $\mathbf{9 . 6} \pm \mathbf{1 . 7}$ \\
\hline L. collurio & $28.2 \pm 5.5$ & $30.1 \pm 5.2$ & $29.5 \pm 4.4$ & $28.0 \pm 3.9$ & $29.7 \pm 4.5$ & $31.0 \pm 5.2$ & $27.9 \pm 4.1$ & $\mathbf{2 9 . 2} \pm \mathbf{4 . 7}$ \\
\hline S. communis & $14.8 \pm 1.9$ & $17.6 \pm 2.2$ & $15.2 \pm 2.2$ & $17.0 \pm 3.1$ & $15.6 \pm 2.3$ & $16.7 \pm 3.1$ & $16.0 \pm 2.7$ & $\mathbf{1 6 . 1} \pm \mathbf{2 . 7}$ \\
\hline
\end{tabular}




\section{DISCUSSION}

In the studied long-distance migrants, considerable variations in the means of the fat level and the body mass between years have been registered. A possible reason for this could be the passage of birds in various migratory stages through the territory of the Balkan Peninsula. The age, sex and population composition of the migrants in particular periods of the season could influence the values of the studied parameters. The average fat levels and body masses should remain equal between the subsequent years if the composition of the migrants is similar. According to our results, the physiological parameters of the birds vary by years. Hence, we could suggest a change of the migrants composition, but the sequence of the populations during the autumn migration must be relatively constant as we have no evidence for the fast changes in the breeding areas of the species. Therefore, the annual variations in the migratory state of the same populations are only possible explanation of our results.

External factors, i.e. the environmental conditions during the period of the passage and the habitat quality in the stopover sites are also known to influence the fat accumulation of migrating birds (Yong et al. 1998). They, as well as the lack of selective environment, are more likely to have direct impact on the values of the fat level and body mass registered in NE Bulgaria. Willow Warblers caught in Sahara desert, a highly selective environment, has shown low variations $(0.4 \mathrm{~g})$ in the body mass between years (Biebach 1990); in contrast, the birds of the same species at the Kalimok station have considerably bigger variation $(S D=1.7 \mathrm{~g})$.

The most numerous species, the Sedge Warbler, allows a more precise analysis and comparisons of the studied parameters by years. The variations in the fat level and the body mass were similar but the latter is more convenient because of the lower subjectivity and the more numerous range classes.

To check whether the age structure of migrants could be a reason for the between years differentiation in studied parameters, the body masses of adults and first year birds were analysed separately (Table 4). Comparison by pairs of all years revealed significant differences in eight cases. In two cases, the significant differences were due to the body mass variation in adults, in other five due to the first year birds and in one because of both ages. Yearly values of body mass of adults caught in Kalimok in 1999 and 2000 were much lower than at Ukrainian station Cholgini (Zakala et al. 2004) in the same years (11.52 and 11.44 versus 12.73 and $12.79 \mathrm{~g}$ ); for immatures 1999 values were the same (11.86 and $11.81 \mathrm{~g})$, while in 2000 Ukrainian birds were significantly heavier (12.28 versus $11.42 \mathrm{~g}$ in Kalimok).

During the course of season the body mass, as assessed in Kalimok, usually grows but there is visible variation in this respect. The linear regression trend line of the body mass indicates the increase, decrease or remains stable during the season (Table 5). The same was found in Cholgini for years 1999 and 2000 (Zakala et al. 2004). 
Table 4

Comparison of the body mass of the Sedge Warblers between different years.

Body mass (mean $\pm S D$ ), number of birds studied $(N)$ and $t$-test values are given.

Levels of significance: ${ }^{*}-p<0.05,{ }^{* *}-p<0.01,{ }^{* * *}-p<0.001$, others $n s$.

\begin{tabular}{|l|l|l|l|l|l|l|l|}
\hline & Mean $\pm S D$ & $N$ & 1997 & 1999 & 2000 & 2001 & 2002 \\
\hline
\end{tabular}

All measured birds

\begin{tabular}{|c|c|c|c|c|c|c|c|}
\hline 1997 & $11.87 \pm 2.55$ & 63 & & & & & \\
\hline 1999 & $11.79 \pm 1.47$ & 245 & 0.226 & & & & \\
\hline 2000 & $11.46 \pm 1.50$ & 178 & 1.19 & $\mathbf{2 . 2 6 6} *$ & & & \\
\hline 2001 & $12.01 \pm 1.75$ & 262 & 0.417 & 1.527 & $\mathbf{3 . 5 1} * * *$ & & \\
\hline 2002 & $12.71 \pm 2.23$ & 123 & $\mathbf{2 . 2 2 8} *$ & $\mathbf{4 . 1 6 8} * * *$ & $\mathbf{5 . 4 3 9} * * *$ & $\mathbf{3 . 0 8 8} * *$ & \\
\hline 2003 & $12.09 \pm 1.77$ & 142 & 0.615 & 1.674 & $\mathbf{3 . 3 4 1} * * *$ & 0.416 & $\mathbf{2 . 5 0 8 *}$ \\
\hline
\end{tabular}

First year birds

\begin{tabular}{|c|c|c|c|c|c|c|c|}
\hline 1997 & $11.13 \pm 1.65$ & 35 & & & & & \\
\hline 1999 & $11.81 \pm 1.51$ & 216 & $\mathbf{2 . 2 9 7} *$ & & & & \\
\hline 2000 & $11.42 \pm 1.61$ & 130 & 0.931 & $\mathbf{2 . 2 4 8 *}$ & & & \\
\hline 2001 & $11.75 \pm 1.59$ & 219 & $\mathbf{2 . 0 5 9} *$ & 0.458 & 1.832 & & \\
\hline 2002 & $12.72 \pm 2.23$ & 108 & $\mathbf{4 . 5 2 9} * * *$ & $\mathbf{3 . 8 3 3} * * *$ & $\mathbf{5 . 0 7 6}^{* * *}$ & $\mathbf{4 . 0 8 6}^{* * *}$ & \\
\hline 2003 & $11.77 \pm 1.47$ & 94 & $\mathbf{1 . 9 9 8 *}$ & 0.262 & 1.658 & 0.107 & $\mathbf{3 . 6 4 8}^{* * *}$ \\
\hline
\end{tabular}

Adult birds

\begin{tabular}{|c|c|c|c|c|c|c|c|}
\hline 1997 & $11.89 \pm 2.61$ & 18 & & & & & \\
\hline 1999 & $11.52 \pm 0.99$ & 20 & 0.564 & & & & \\
\hline 2000 & $11.44 \pm 1.01$ & 46 & 0.711 & 0.303 & & & \\
\hline 2001 & $13.36 \pm 1.92$ & 38 & $\mathbf{2 . 1 3 5 *}$ & $\mathbf{4 . 8 2} * * *$ & $\mathbf{5 . 5 6 8} * * *$ & & \\
\hline 2002 & $12.71 \pm 2.31$ & 14 & 0.947 & 1.82 & $\mathbf{2 . 0 0 6 *}$ & 0.934 & \\
\hline 2003 & $12.71 \pm 2.13$ & 48 & 1.191 & $\mathbf{3 . 1 3 4} *$ & $\mathbf{3 . 7 1} * * *$ & 1.49 & 0.009 \\
\hline
\end{tabular}

Table 5

Slope of the linear regression trendline in the body mass of Sedge Warblers in the course of autumn.

Number of weighed birds $(N)$

and significance level $(p<0.05$ in bold) are given.

\begin{tabular}{|c|c|c|c|}
\hline & $N$ & Slope & $p$ \\
\hline 1997 & 63 & 0.039 & $\mathbf{0 . 0 1 5}$ \\
1998 & 10 & - & - \\
1999 & 245 & 0.017 & $\mathbf{0 . 0 0 1}$ \\
2000 & 178 & 0.012 & $\mathbf{0 . 0 2 3}$ \\
2001 & 262 & -0.012 & 0.069 \\
2002 & 123 & 0.024 & $\mathbf{0 . 0 0 3}$ \\
2003 & 142 & -0.005 & 0.530 \\
\hline
\end{tabular}


The Willow Warbler, a species known in Bulgaria during migrations only, was a subject of numerous studies on fat accumulation carried out in different parts of its migratory range (Table 6). Data from northern Europe - Ottenby (Sweden) and Helgoland (Germany) - show body masses of Willow Warbler significantly lower than registered in NE Bulgaria. They increase southwards and on the Mediterranean islands (Cyprus and Karpathos), just before the large forthcoming barriers, they show the highest values. There are no differences between our results and those from the coast of Egypt, after the crossing of the Mediterranean Sea. The mean values of the body mass of Willow Warblers from Bulgaria are almost equal to those registered at the rocky desert (northern parts of Egypt) and at a small oasis in Sahara (Algeria). After the desert crossing the mean body mass of the Willow Warblers is approximately equal to the fat-free body mass of the species. The variations in the body mass and the fat level by years and the intermediate values from Bulgaria compared with the same parameters from other places (Table 6) could be explained by the lack of a selective environment in the region allowing the conspecific passage of birds in various body conditions. The realisation of their migration adaptations highly depends on environmental conditions during the period of the passage.

Table 6

Body mass (g) of Willow Warblers on autumn migration in various parts of Europe and Africa

\begin{tabular}{|l|c|r|l|}
\hline \multicolumn{1}{|c|}{ Location } & Mean $\pm S D$ & $N$ & \multicolumn{1}{c|}{ References } \\
\hline Ottenby (Sweden) & $8.2 \pm 0.7$ & 81 & Akesson et al. (1995) \\
Bukowo (Poland) & $8.8 \pm 0.98$ & 2349 & P. Busse (pers. comm.) \\
Helgoland (Germany) & $8.6 \pm 0.96$ & 161 & Dierschke and Bindrich (2001) \\
\hline NE Bulgaria & $\mathbf{9 . 6} \pm \mathbf{1 . 6 5}$ & $\mathbf{7 7 2}$ & Present paper \\
Karpathos Is. (Greece) & $10.9 \pm 1.28$ & 82 & Biebach (1990) \\
Cyprus & 9.8 & 271 & Moreau (1969) \\
\hline Algerian Sahara & $9.8 \pm 1.1$ & 104 & Bairlein (1992) \\
Dhleil (Jordan) & $9.5 \pm 1.18$ & 98 & P. Busse (pers. comm.) \\
Egypt - coast & $9.2 \pm 1.31$ & 43 & Moreau and Dolp (1970) \\
Egypt - desert & $9.7 \pm 1.22$ & 427 & Biebach et al. (1986) \\
Port Sudan (Sudan) & 7.0 & 95 & Biebach after Nikolaus (1990) \\
\hline
\end{tabular}

\section{ACKNOWLEDGEMENTS}

We would like to thank the staff of the Kalimok Biological Station and all bird ringers who participated in the trapping activities. We are also most grateful to Dr Boyko Georgiev for his editorial help. This study was supported with ringing equipment and funds by South East European Bird Migration Network (SEEN). 


\section{REFERENCES}

Akesson S., Hedenstrom A., Hasselquist D. 1995. Stopover and fat accumulation in passerine birds in autumn at Ottenby, southeastern Sweden. Ornis Svecica 5: 81-91.

Akriotis T. 1998. Post-breeding migration of Reed and Great Reed Warblers breeding in southeast Greece. Bird Study 45: 344-352.

Bairlein F. 1992. Recent prospects on trans-Saharan migration of songbirds. Ibis 134: 41-46.

Bairlein F. 1995. Manual of field methods. European-African songbird migration network. Institut für Vogelforschung, Wilhelmshaven.

Berthold P. 2001. Bird migration: A general survey. Oxford Univ. Press, Oxford.

Biebach H. 1990. Strategies of Trans-Sahara Migrants. In: Gwinner E. (Ed.). Bird migration. Springer Verlag, Berlin-Heidelberg: pp. 352-367.

Biebach H., Friedrich W., Heine G. 1986. Interaction of body mass, fat, foraging and stopover period in trans-Sahara migrating passerine birds. Oecologia 69: 370-379.

Busse P. 2000. Bird station manual. SEEN, University of Gdańsk, Gdańsk.

Dierschke V., Bindrich F. 2001. Body condition of migrant passerines crossing a small ecological barrier. Vogelwarte 41: 119-132.

Dolnik V.R. 1975. [Migratory disposition in birds.] Nauka, Moscow. (In Russian).

Kaiser A. 1993. A new multi-category classification of subcutaneous fat deposits of songbirds. J. Field Ornithol. 64: 246-255.

Moreau R.E. 1969. Comparative weights of some trans-Sahara migrants at intermediate points. Ibis 111: 621-624.

Moreau R.E., Dolp R.M. 1970. Fat, water, weights and wing-lengths of autumn migrants in transit on the northwest coast of Egypt. Ibis 112: 209-228.

Schaub M., Jenni L. 2000. Fuel deposition of three passerine bird species along the migration route. Oecologia 122: 306-317.

Yong W., Finch D.M., Moore F.R., Kelly J.F. 1998. Stopover ecology and habitat use of migratory Wilson's Warblers. Auk 115: 829-842.

Zakala O., Shydlovskyy I., Busse P. 2004. Variation in body mass and fat reserves of the Sedge Warbler (Acrocephalus schoenobaenus) on autumn migration in the L'viv Province (W Ukraine). Ring 26, 2: 55-69. 